\title{
Hurricane Allen destroys Jamaican coral reefs
}

from J. D. Woodley

HURRICANE Allen, which traversed the Caribbean in early August, was the second strongest ever recorded with wind speeds approaching $300 \mathrm{kph}(185 \mathrm{mph})$. Fortunately, its track was mostly over the sea but, while the islands were spared the impact of extreme winds, they were exposed to enormous storm-generated waves. In the small hours of Wednesday 6th August, Allen passed within $50 \mathrm{~km}$ of the north-east coast of Jamaica. Severe wind damage occurred to the forests of the Blue Mountains and the banana plantations of the adjacent lowlands. Huge waves beat upon the eastern and northern shores, claiming several lives. Houses built on cliffs $12 \mathrm{~m}$ above the sea were destroyed. Beneath sea-level, the spectacular fringing coral reefs suffered considerable damage.

The Discovery Bay Marine Laboratory of the University of the West Indies is at a site is in the middle of the north coast and not in the area hardest hit but, after the hurricane waves subsided, the water was turbid with fine sediment and pulverised tissues; there was a smell of dead corals, gorgonians and sponges. Death and injury to these and other organisms have now been assessed. Branching corals have been smashed, massive corals toppled or split, and plate-like ones fractured or torn off the reef slopes. Gorgonians and sponges have been ripped away or broken, echinoids destroyed and many fishes injured too. Physical damage varies with exposure and submarine profile, but in some places extends below $-50 \mathrm{~m}$. Tons of sediment have been removed from the reef slopes and terraces. Sand-blasting and flying missiles have caused extensive abrasion, especially in the shallowest zones, where almost total destruction prevails. Before the storm, luxuriant stands of elkhorn coral (Acropora palmata) dominated the breaker zone from 0 to $-6 \mathrm{~m}$ (Fig. 1). This species is well able to resist the forces of ordinary breaking waves, but evidently not those generated by a severe hurricane. It has been reduced to rubble (Fig. 2) and some of this flung on to the reef flat, forming islands where none was before.

J. D. Woodley is Director of the Discovery Bay Marine Laboratory, Discovery Bay, Jamaica.

the IMF for the solar neighbourhood. (2) Are there any galaxies intermediate between the high and low infrared luminosity galaxies? (3) What mechanism starts and sustains the star formation activity?

The correlation between neutral hydrogen velocity width and integrated magnitude for galaxies (Fisher-Tully relation) can be used to determine the Hubble flow velocity, $\mathrm{H}_{0}$, and hence the extragalactic distance scale. M. Aaronson (Steward Observatory) discussed his latest results using infrared magnitudes which

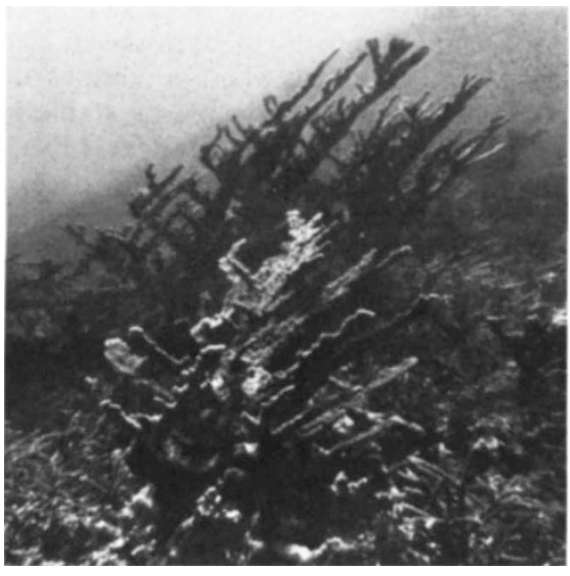

Fig 1 A stand of Acropora palmata in the breaker zone before the hurricane.

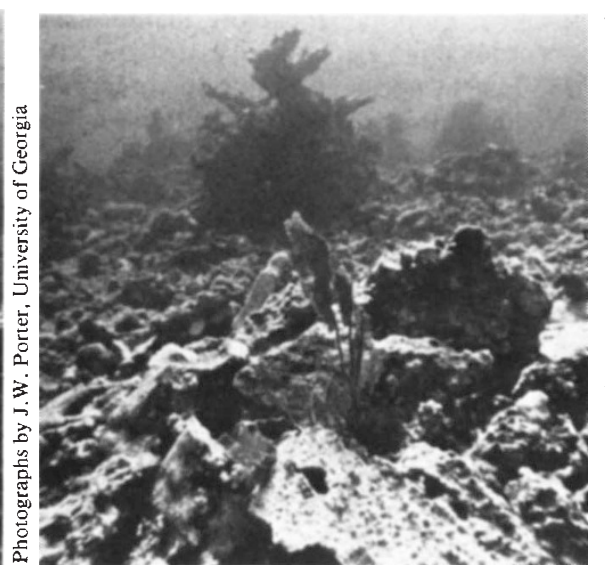

Fig 2 The breaker zone at the same locality after Hurricane Allen.

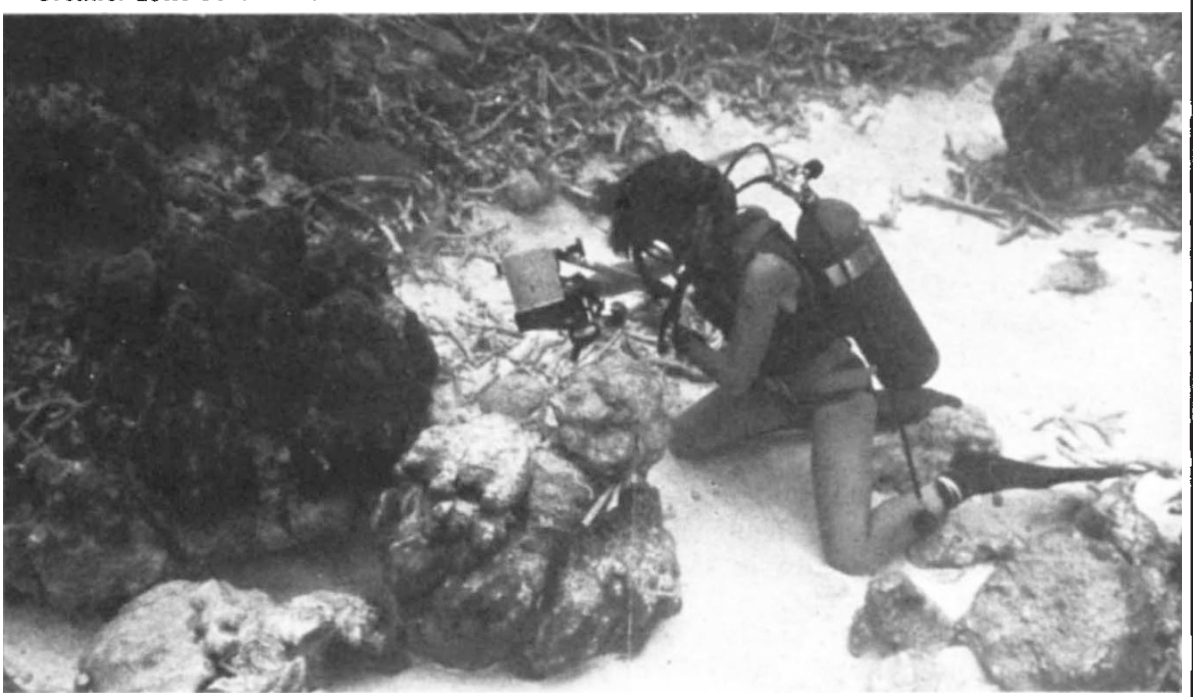

Fig 3 A diver (K. W. Rylaaosdam) photographing newly exposed substratum on an over-turned head of Monastrea annulans at a depth of $-11 \mathrm{~m}$. More bare substratum can be seen where some $30 \mathrm{~cm}$ of sand was removed by the hurricane. In the background are smashed colonies of staghorn coral, Acropora cervicornis.

Studies are continuing on the survival of broken or disturbed corals and other sessile organisms, the healing of injuries, changes in demersal plankton, changes in the reeffish community and the colonization of bare substrata. The last of these, beginning the long process of regenerating a new reef community, is of particular interest. Abrasion, fracture and sediment removal have exposed large areas of new surface for colonization throughout the reef profile (Fig. 3), but especially in shallow water.

give a tighter correlation than the optical magnitudes used in earlier studies. With the exception of galaxies in the Virgo cluster the value of $\mathrm{H}_{0}$ is $95 \pm 4 \mathrm{~km} \mathrm{sec}^{-1}$ $\mathrm{Mpc}^{-1}$. Judging from the reaction to Aaronson's talk at the meeting this new value of $\mathrm{H}_{0}$ is being treated very seriously. Since the canonical value of $55 \mathrm{~km} \mathrm{sec}-1$ $\mathrm{Mpc}^{-1}$ by Sandage and Tamman is very much less, it is clear that the origin of the discrepancy between these values must be urgently sought. For Virgo $\mathrm{H}_{\mathrm{o}}=65 \mathrm{~km}$ $\mathrm{sec}^{-1} \mathrm{Mpc}^{-1}$ which can be interpreted as an infall of the local group of galaxies towards
Already, there are massive blooms of various green algae. Will the subsequent communities resemble the pre-existing ones, and how long will they take to develop? In most of the reef zones at Discovery Bay, the disturbance was spectacular but not totally destructive; recovery is likely to occur within a few years. Where extreme damage has occurred, that is, in shallow water and progressively deeper on reefs further east, it is possible that 'recovery' will take decades.

Virgo at a radial velocity of $480 \mathrm{~km} \mathrm{sec}^{-1}$.

The vigorous growth of the subject makes it likely that this first symposium devoted to all major fields of infrared astronomy may well be the last with such a wide compass. The direction this expanding field of research will go in is not easy to predict. However it is clear that infrared observations of redshifted galaxies will play a vital role in the solution of many of the most important cosmological problems, a point stressed by M. Longair (University of Cambridge) at the end of the symposium. 